\title{
ASSOCIATIONS BETWEEN NUTRITIONAL STATUS AND HEALTH-RELATED QUALITY OF LIFE AMONG LONG-TERM CARE RESIDENTS IN HELSINKI
}

\author{
K.S. SALMINEN ${ }^{1,2}$, M.H. SUOMINEN ${ }^{1}$, H. SOINI ${ }^{3}$, H. KAUTIAINEN ${ }^{1}$, N. SAVIKKO ${ }^{1}$, R.K.T. SAARELA ${ }^{4}$, \\ S. MUURINEN ${ }^{1}$, K.H. PITKALA ${ }^{1,5}$
}

\begin{abstract}
1. University of Helsinki, Department of General Practice and Primary Health Care, Helsinki, Finland; 2. Vantaa Social Welfare and Health Care, Vantaa, Finland; 3. City of Helsinki,

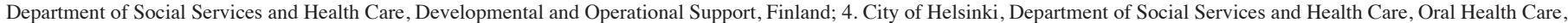
Finland; 5. Helsinki University Hospital, Unit of Primary Health Care, Finland. Corresponding author: Karoliina Sofia Salminen, Helsingin Yliopisto, Helsinki, Finland, karoliina.salminen@helsinki.fi
\end{abstract}

\begin{abstract}
Objectives: We evaluated the associations between nutritional status and health-related quality-oflife (HRQoL) among older long-term care residents in Helsinki. Design and participants: All 3767 older ( $\geq 65$ years) long-term care residents in Helsinki in 2017 were invited to participate in this cross-sectional study. After refusals and exclusions of residents without sufficient information, 2160 residents remained. Measurements: Data on characteristics, nutritional status (Mini Nutritional Assessment, MNA) and HRQoL (15D) were collected by trained nurses. Results: Of the participants, $64 \%$ were at-risk of malnutrition and $18 \%$ suffered from malnutrition. Residents in the "malnourished" group were more dependent in activities of daily living (ADL) functioning, suffered more often from dementia, had lower cognitive level, used less medications, and were eating more often inadequately. HRQoL was statistically significantly associated with MNA total score in both female and male residents. There was a curvilinear correlation between MNA and 15D score in females: 0.50 (95\% CI 0.46 to 0.53 ) and males: 0.56 (95\% CI 0.50 to 0.61$)$. In partial correlation analysis, all dimensions of 15D, except for sleeping and breathing, were positively associated with MNA score. In these analyses no significant differences emerged between males and females when the results were adjusted for age and dementia. Conclusions: Nutrition plays an important role in HRQoL among older long-term care residents.
\end{abstract}

Key words: Nutrition, MNA, health-related quality-of-life, nursing home, long-term care.

\section{Introduction}

About $14-21 \%$ of nursing home residents have suffered from malnutrition when measured with the Mini Nutritional Assessment (MNA) tool (1). The relationship between nutrition status and health-related quality of life (HRQoL) among older people has not been extensively studied. In home-dwelling older people poorer nutritional status has been associated with poorer HRQoL (2-6). However, studies exploring the relationship between nutritional status and HRQoL are scarce in institutional settings. In an early study, a low body-mass index (BMI) indicative of protein-caloric malnutrition was associated with poor quality of life (QoL) (7). Better nutritional status has been shown to be associated with better psychological wellbeing (PWB) among nursing home residents (8).

HRQoL has been considered a key goal for care of long-term residents (4). HRQoL is designed to measure self-perceived health, encompassing the physical, functional, social and emotional well-being of an individual (4). Depression is known to be associated with decreased HRQoL among older residents of nursing homes $(2,9-13)$. High independence in activities of daily life (ADL) has been associated with higher HRQoL in some $(14,15)$, but not all studies (11). Malnutrition is a risk factor for deterioration of functional status in older adults, which is considered one dimension of HRQoL $(4,7)$. Thus, nutritional status may be a mediator between functional status and HRQoL.

Thus, there is a paucity of research exploring the relationship between nutritional status and HRQoL according to gender in institutionalized residents. To our knowledge, no studies have investigated which dimensions of HRQoL are associated with poorer nutritional status. The aim of this study was to explore the association of Mini-Nutritional Assessment (MNA) score with HRQoL according to a 15D measure in long-term care residents aged over 65 -years living Helsinki, Finland. In addition, we examined which dimensions of HRQoL are associated with nutritional status in males and females.

\section{Methods}

\section{Study sample}

The study was designed to obtain a comprehensive picture of nutritional status, nutritional care, and related factors of older residents in institutional settings. We collected cross-sectional data in all long-term care facilities (nursing homes and assisted living facilities) in Helsinki, Finland. Assisted living facilities in Finland provide 24-hour care with a registered nurse in charge of the unit. The residents are similar to those in nursing homes, but the environment is more home-like. Altogether 54 long-term facilities with 3767 eligible residents participated in the study. The inclusion criteria were: age $\geq 65$ years, living in long-term care, and sufficient information availability on demographic factors, MNA, and HRQoL. Altogether 2545 (68\%) residents provided informed consent. Of these, 2160 had data on both MNA and 15D available and were included. The dropouts were either refusals or residents with dementia having Published online March 21, 2019, http://dx.doi.org/10.1007/s12603-019-1182-1 
Table 1

The Study population' characteristics according to nutrition status

\begin{tabular}{|c|c|c|c|c|}
\hline Variable & $\begin{array}{c}\begin{array}{c}\text { Normal nutritional status } \\
(<23.5 \text { points }) \\
\mathrm{n}=395\end{array} \\
\end{array}$ & $\begin{array}{c}\text { Risk of malnutrition } \\
\begin{array}{c}(17-23.5 \text { points }) \\
n=1383\end{array} \\
\end{array}$ & $\begin{array}{c}\text { Malnutrition } \\
(<17 \text { points }) \\
\mathbf{n}=\mathbf{3 8 2} \\
\end{array}$ & P-value ${ }^{1}$ \\
\hline Female, n (\%) & $272(69)$ & $1021(74)$ & $292(76)$ & 0.016 \\
\hline Age, mean $\left(\mathrm{SD}^{2}\right)$ & $83(8)$ & $84(8)$ & $85(8)$ & 0.15 \\
\hline Education ( $\leq 8$ years), $\mathrm{n}(\%)$ & $151(41)$ & $528(42)$ & $142(44)$ & 0.42 \\
\hline Charlson $^{3}$, mean (SD) & $2.0(1.4)$ & $2.1(1.3)$ & $2.0(1.3)$ & 0.71 \\
\hline Stroke, n (\%) & $83(21)$ & $344(25)$ & $82(21)$ & 0.86 \\
\hline Number of medications, mean $\left(\mathrm{SD}^{2}\right)$ & $9.8(3.6)$ & $8.9(3.5)$ & $8.1(3.6)$ & $<0.001$ \\
\hline $\mathrm{CDR}^{4}$, memory item $\geq 2, \mathrm{n}(\%)$ & $134(35)$ & $822(59)$ & $287(75)$ & $<0.001$ \\
\hline $\mathrm{CDR}^{4}$, personal care item $\geq 2, \mathrm{n}(\%)$ & $283(74)$ & $1245(92)$ & $368(99)$ & $<0.001$ \\
\hline
\end{tabular}

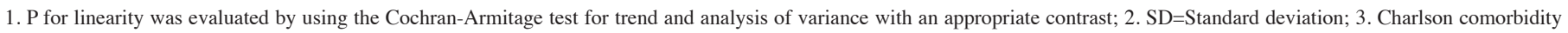
index (Charlson et al. 1987); 4. CDR=Clinical Dementia Rating (Hughes et al. 1982); 5. BMI=body mass index $\left(\mathrm{kg} / \mathrm{m}^{2}\right)$

no proxy to give informed consent.

\section{Measurements}

Data were collected by registered nurses in March 2017. In each ward, a thoroughly trained nurse assessed residents' nutritional status by the MNA and retrieved demographic information, diagnoses, and use of medications from medical records. They assessed HRQoL according to the 15D instrument.

The MNA gives a maximum score of 30 points. Less than 17 points indicates malnutrition, 17-23.5 risk of malnutrition, and 24 or more good nutrition status $(16,17)$. The MNA is validated and widely used internationally (17). In addition, each resident was weighed and body mass index (BMI) calculated as weight divided by height squared $(\mathrm{kg} / \mathrm{m} 2)$.

The 15D instrument is a validated, generic measure for HRQoL (18). The dimensions of 15D are mobility, vision, hearing, breathing, sleeping, eating, speech, excretion, usual activities, mental function, discomfort and symptoms, depression, distress, vitality and sexual activity. 15D can be completed during an interview with the subject or completed by proxy. It combines the advantages of a profile and a preferencebased, single-index measure (18). Score 0 indicates the poorest HRQoL and 1 indicates perfect HRQoL. The 15D scores are reliable, sensitive and responsive to change (18). The nurse most familiar with resident was interviewed if the subject was cognitively impaired. The 15D score has been calculated from all dimensions of the instrument. In this study, all participants responded to the question concerning sexuality "My state of health makes sexual activity almost impossible". Thus, this question was excluded from the partial correlation analysis.
Comorbidities were evaluated with the Charlson Comorbidity Index (CCI), which takes into account both the number and severity of a person's medical conditions. High score indicates a greater burden from comorbidities (19).

Cognitive functioning and dependence in ADL were assessed with questions retrieved from the Clinical Dementia Rating Scale (CDR). The "memory" question was used to evaluate the resident's stage of cognition $(0=$ no memory problems, $0.5=$ possible memory problems, $1=$ mild problems, $2=$ moderate problems, or $3=$ severe problems) and was categorized into two groups: those with CDR $<2$ and those with $\mathrm{CDR} \geq 2$. The resident's dependence in ADL functions was evaluated by CDR "personal care" question ( $1=$ totally independent; $2=$ needs prompting, $3=$ requires assistance in dressing, personal hygiene, and keeping of personal belongings, $4=$ requires much help with personal care; often incontinent). CDR "personal care" $\geq 2$ was defined as dependence in ADLs.

The use of snacks was inquired as follows "Does the resident eat snacks between meals?" (yes/no). The amount of offered food eaten by the resident was evaluated with the question "How much does the residents on average eat from the main meal?" with the five options, "eats only a little, eats less than half, eats half their meal, eats most of their meal or eats all or nearly all of their meal". The nurses were informed to use images of model portions to estimate this. The responses "eats only a little and eats less than half" were dichotomized as eats inadequately and the response "eats half their meal, eats most of their meal or eats all or nearly all of their meal" as eats adequately.

The local ethics committee of Helsinki University Hospital approved the study. An informed consent was acquired from all 


\section{ASSOCIATIONS BETWEEN NUTRITIONAL STATUS AND HEALTH-RELATED QUALITY OF LIFE}

participants or in case of moderate-severe dementia from their closest proxies.

\section{Statistical analysis}

The descriptive statistics are presented as means with SDs or as counts with percentages. Statistical significances for the unadjusted hypothesis of linearity across categories of MNA $(<23.5,17 .-23.5$ and $<17)$ were evaluated by using the Cochran-Armitage test for trend and analysis of variance with an appropriate contrast. In the case of violation of the assumptions (e.g. non-normality), a bootstrap-type test was used. The relationships of MNA and 15D-score was evaluated by use of quadratic model (curvilinear correlation). Adjusted correlation (partial) coefficients MNA and 15D dimensions were calculated by the Pearson method, using Sidak adjusted probabilities. The normality of the variables was tested by using the Shapiro-Wilk W-test. Stata 15.1 (StataCorp LP, College Station, TX, USA) was used for the analysis.

\section{Results}

The mean age of participants was 84 years, and $73 \%$ were females. According to MNA, 64\% were at-risk of malnutrition and $18 \%$ suffered from malnutrition. Residents in the "malnourished" group were more often females, had lower BMI, and suffered more often from dementia. They had lower a level of cognition according to CDR, less medications, and were more dependent in ADL functioning. They ate more often inadequately. Characteristics of the study sample according to nutrition stage are provided in Table 1.

The mean 15D score was 0.61 (SD 0.13) among females and 0.62 (SD 0.14) among males. Male residents had better HRQoL than female residents $(\mathrm{p}=0.020)$. Among females with a normal nutritional status the mean 15D score was 0.71 (SD 0.12), among those at-risk of malnutrition 0.61 (SD 0.12), and among malnourished residents 0.52 (SD 0.10). Among males with a normal nutritional status, the mean $15 \mathrm{D}$ score was 0.74 (SD 0.11 ), among those at-risk of malnutrition 0.61 (SD 0.12), and among malnourished residents 0.51 (SD 0.10).

There was a curvilinear correlation between MNA and 15D score (Figure 1). The curvilinear correlation among men was $0.56(95 \% \mathrm{Cl} 0.50$ to 0.61$)$ and among women $0.50(95 \%$ 0.46 to 0.53 ) (Figure 1). The $15 \mathrm{D}$ score started to increase among those at-risk of malnutrition, and it continued to increase linearly among those who were well-nourished. HRQoL was significantly associated with MNA score in both female and male residents.

Results from the partial correlation analysis between the MNA total score and the 14 dimensions of the 15D according to gender are presented in Figure 2. All dimensions of the 15D, except for sleeping and breathing, were associated with the MNA score in both genders. The strongest correlations for the 15D dimensions were found in "eating" and "mobility" in both genders. No significant differences emerged between males and females in partial correlations of the 14 dimensions of $15 \mathrm{D}$ with MNA total score after adjustment for age and dementia.

\section{Figure 1}

Relationship between Mini Nutritional Assessment (MNA) Score (16) and health-related quality-of-life according to 15D (18) score in females and males. Curvilinear correlation with 95\% confidence intervals (in gray). The dashed lines represent the cut-off points for malnutrition ( $<17$ points in MNA), at-risk of malnutrition (17 - 23.5 points) and normal nutritional status (>23.5 points)

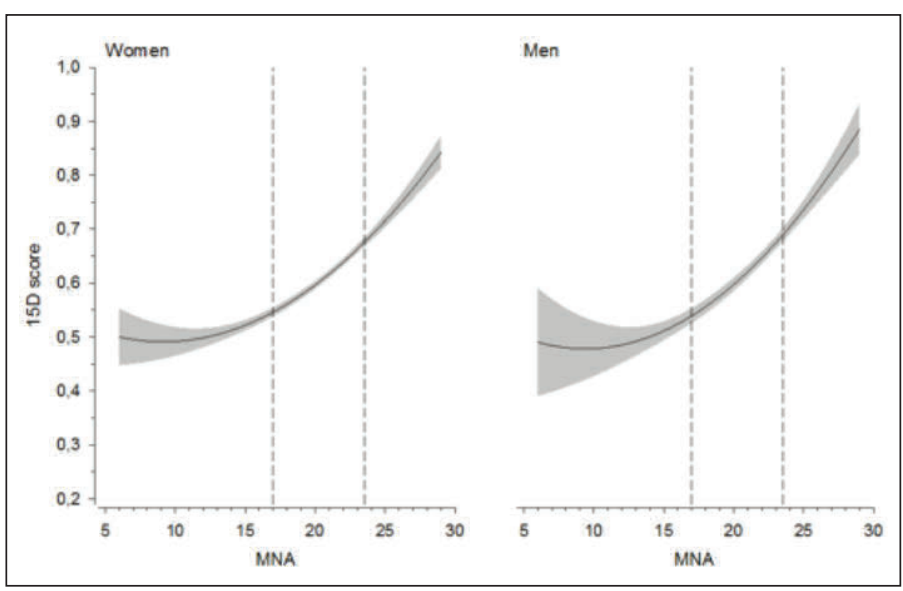

Figure 2

Partial correlation with $95 \%$ confidence intervals between dimensions of 15D (18) and Mini Nutritional Assessment (MNA) total score (16) in male and female residents. Adjusted for age and dementia

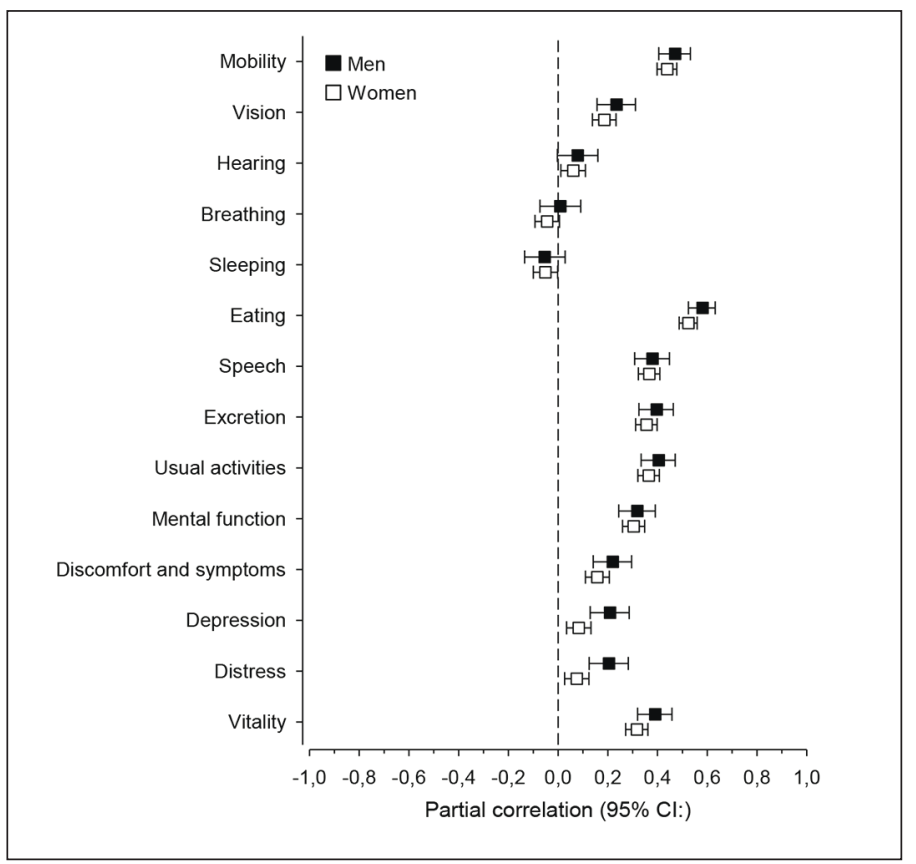




\section{THE JOURNAL OF NUTRITION, HEALTH \& AGING@}

\section{Discussion}

Nutritional status was significantly associated with HRQoL among institutionalized residents of both sexes. A curvilinear correlation existed between MNA and 15D score in such way that 15D score had a "floor effect" among those who were severely malnourished. The $15 \mathrm{D}$ score increased rapidly in a linear manner among those who were at-risk of malnutrition or had normal nutritional status. Of dimensions of 15D, mobility and eating had the strongest partial correlation with MNA, whereas sleeping and breathing did not have a significant association with MNA. There were no significant differences between males and females in partial correlation of the 14 dimensions of the 15D with MNA total score after adjustment for age and dementia.

Strength of this study are large sample size and the fairly good representativeness of the sample. All residents who were residing in nursing homes and assisted living facilities in the city of Helsinki were invited to participate. However, the response rate was only $68 \%$. Of these, $85 \%$ had both MNA and 15D scores available. A limitation of the study is its cross-sectional nature. Thus, whether HRQoL has a causal relationship with nutritional status cannot be concluded. However, to our knowledge, there are no previous studies exploring the relationship between MNA and HRQoL in nursing homes. Furthermore, the associations between different dimensions of HRQoL and nutrition according to gender have not been explored in earlier.

Previous research has revealed that malnutrition is common among aged residents in nursing homes $(1,20-23)$. In the metaanalysis the prevalence of malnutrition varied between $14 \%$ and $21 \%$ in nursing homes (1). In our study, the prevalence of malnutrition was $18 \%$. Educational attempts have been made since 2003 to improve nutritional care in nursing homes in Helsinki $(24,25)$. Finnish nutritional guidelines were published in 2010 (26). An improvement has taken place despite increasing disabilities among institutionalized residents (25). Residents' mean age is higher and they are more disabled now than ten years ago (25). Many comorbidities, high age and increased disability should increase the risk of malnutrition (1). Lower BMI, decreased level of cognition, lower number of medication and dependency in ADL were associated with malnutrition. These observations are in line with previous studies (20).

Our results are consistent with earlier studies exploring the association of nutrition status with HRQoL or psychological well-being. In both community-living and non-institutionalized older people, malnutrition has been associated with poor HRQoL (27-29).

In previous studies HRQoL has been poorer in females than in males among non-institutionalized and communityliving individuals $(3,27,30)$. One explanation for the gender differences in HRQoL could be that females more willingly report health problems than males and they have higher expectations of health and function (27).

Impairments in ADL - an important dimension of HRQoL - are associated with reduced QoL in nursing home residents $(31,32)$. The impairments in ADL has been associated with decline in QoL in several studies $(10,14,33,34)$. In our study, impairments in ADL in the 15D dimensions of mobility, excretion, usual activities, and even eating were associated with the MNA score. As items in both MNA and 15D measure ADL dimensions, it is not unexpected that nutrition stage and HRQoL were associated. However, these findings do not explain why the curvilinear correlation between the MNA and $15 \mathrm{D}$ was so strong.

In addition to ADL impairments, mental function in $15 \mathrm{D}$ indicating cognition was also significantly correlated with the MNA score. This is also understandable since cognitive stage was associated with nutritional status. Both dementia and depression are included in one item of the MNA. It is obvious that eating and vitality were associated with the MNA score.

No association existed between breathing or sleeping and the MNA score. There may be other confounders affecting these dimensions besides the MNA. However, all of the factors that predict HRQoL in long-term care residents are not wellknown. The causality between nutrition status and HRQoL needs further studies. Nutrition intake and nutritional status are potentially mediators between functional status and HRQoL.

\section{Conclusions}

Nutritional status according to the MNA is significantly associated with HRQoL in both male and female residents in institutional settings. Our study emphasizes that nutrition is an very important element in maintaining HRQoL. Additional means to support nutrition in older people should be studied.

Acknowledgements: This study was supported by Päivikki and Sakari Sohlberg Foundation. The sponsor did not have any role in study design, analysis or interpretation of data, nor writing the report or decision to submit this article. The authors were independent researcher not associated with the funder. Open access funding provided by University of Helsinki including Helsinki University Central Hospital.

Conflict of interest: None.

Ethical standards: The local ethics committee of Helsinki University Hospital approved the study.

Open Access: This article is distributed under the terms of the Creative Commons Attribution 4.0 International License (http://creativecommons.org/licenses/by/4.0/), which permits use, duplication, adaptation, distribution and reproduction in any medium or format, as long as you give appropriate credit to the original author(s) and the source, provide a link to the Creative Commons license and indicate if changes were made.

\section{References}

1. Cereda E, Pedrolli C, Klersy C, Bonardi C, Quarleri L, Cappello S, Turri A, Rondanelli M, Caccialanza R. Nutritional status in older persons according to healthcare setting: A systematic review and meta-analysis of prevalence data using MNA((R)). Clin Nutr 2016;35:1282-1290. doi: S0261-5614(16)00099-6 (pii).

2. Borowiak E, Kostka T. Predictors of quality of life in older people living at home and in institutions. Aging Clin Exp Res 2004;16:212-220.

3. Jimenez-Redondo S, Beltran de Miguel B, Gomez-Pavon J, Cuadrado Vives C. Non-institutionalized nonagenarians health-related quality of life and nutritional status: is there a link between them? Nutr Hosp 2014;30:602-608. doi: 10.3305/ 


\section{ASSOCIATIONS BETWEEN NUTRITIONAL STATUS AND HEALTH-RELATED QUALITY OF LIFE}

nh. 2014.30 .3 .7174 (doi).

4. Jimenez-Redondo S, Beltran de Miguel B, Gavidia Banegas J, Guzman Mercedes L, Gomez-Pavon J, Cuadrado Vives C. Influence of nutritional status on health-related quality of life of non-institutionalized older people. J Nutr Health Aging 2014;18:359364. doi: 10.1007/s12603-013-0416-x (doi).

5. Hernandez-Galiot A, Goni I. Quality of life and risk of malnutrition in a homedwelling population over 75 years old. Nutrition 2017;35:81-86. doi: S08999007(16)30236-2 (pii).

6. Rasheed S, Woods RT. Malnutrition and quality of life in older people: a systematic review and meta-analysis. Ageing Res Rev 2013;12:561-566. doi: 10.1016/j. arr.2012.11.003 (doi)

7. Crogan NL, Pasvogel A. The influence of protein-calorie malnutrition on quality of life in nursing homes. J Gerontol A Biol Sci Med Sci 2003;58:159-164.

8. Muurinen S, Savikko N, Soini H, Suominen M, Pitkala K. Nutrition and psychological well-being among long-term care residents with dementia. J Nutr Health Aging 2015;19:178-182. doi: 10.1007/s12603-014-0519-z (doi).

9. Banerjee S, Samsi K, Petrie CD, Alvir J, Treglia M, Schwam EM, del Valle M. What do we know about quality of life in dementia? A review of the emerging evidence on the predictive and explanatory value of disease specific measures of health related quality of life in people with dementia. Int J Geriatr Psychiatry 2009;24:15-24. doi: 10.1002/gps.2090 (doi).

10. Barca ML, Engedal K, Laks J, Selbaek G. Quality of life among elderly patients with dementia in institutions. Dement Geriatr Cogn Disord 2011;31:435-442. doi: 10.1159/000328969 (doi).

11. Beerens HC, Zwakhalen SM, Verbeek H, Ruwaard D, Hamers JP. Factors associated with quality of life of people with dementia in long-term care facilities: a systematic review. Int J Nurs Stud 2013;50:1259-1270. doi: 10.1016/j.ijnurstu.2013.02.005 (doi).

12. Ghimire S, Baral BK, Pokhrel BR, Pokhrel A, Acharya A, Amatya D, Amatya P, Mishra SR. Depression, malnutrition, and health-related quality of life among Nepali older patients. BMC Geriatr 2018;18:191-018-0881-5. doi: 10.1186/s12877-018-08815 (doi).

13. Smoliner $\mathrm{C}$, Norman $\mathrm{K}$, Wagner $\mathrm{KH}$, Hartig W, Lochs $\mathrm{H}$, Pirlich M. Malnutrition and depression in the institutionalised elderly. Br J Nutr 2009;102:1663-1667. doi: 10.1017/S0007114509990900 (doi).

14. Miguel S, Alvira M, Farré M, Risco E, Cabrera E, Zabalegui A. Quality of life and associated factors in older people with dementia living in long-term institutional care and home care. European Geriatric Medicine 2016;7:346-351. doi: https://doi-org. libproxy.helsinki.fi/10.1016/j.eurger.2016.01.012.

15. Jing W, Willis R, Feng Z. Factors influencing quality of life of elderly people with dementia and care implications: A systematic review. Arch Gerontol Geriatr 2016;66:23-41. doi: 10.1016/j.archger.2016.04.009 (doi).

16. Vellas B, Guigoz Y, Garry PJ, Nourhashemi F, Bennahum D, Lauque S, Albarede $\mathrm{J}$. The mini nutritional assessment (MNA) and its use in grading the nutritional state of elderly patients. Nutrition 1999;15:116-122. doi: https://doi-org.libproxy.helsinki. fi/10.1016/S0899-9007(98)00171-3.

17. Guigoz Y. The Mini Nutritional Assessment (MNA) review of the literature--What does it tell us? J Nutr Health Aging 2006;10:466-85; discussion 485-7.

18. Sintonen H. The $15 \mathrm{D}$ instrument of health-related quality of life: properties and applications. Ann Med 2001;33:328-336. doi: 10.3109/07853890109002086.

19. Charlson ME, Pompei P, Ales KL, MacKenzie CR. A new method of classifying prognostic comorbidity in longitudinal studies: development and validation. J Chronic
Dis $1987: 40 \cdot 373-383$

20. Bell CL, Lee AS, Tamura BK. Malnutrition in the nursing home. Curr Opin Clin Nutr Metab Care 2015;18:17-23. doi: 10.1097/MCO.0000000000000130 (doi).

21. Saletti A, Lindgren EY, Johansson L, Cederholm T. Nutritional status according to mini nutritional assessment in an institutionalized elderly population in Sweden. Gerontology 2000;46:139-145. doi: 22149 (pii).

22. Chan M, Lim YP, Ernest A, Tan TL. Nutritional assessment in an Asian nursing home and its association with mortality. J Nutr Health Aging 2010;14:23-28.

23. Soini H, Suominen MH, Muurinen S, Strandberg TE, Pitkälä KH. Malnutrition according to the mini nutritional assessment in older adults in different settings. J Am Geriatr Soc 2011;59:765-766. doi: 10.1111/j.1532-5415.2011.03339.x.

24. Suominen M, Muurinen S, Routasalo P, Soini H, Suur-Uski I, Peiponen A, FinneSoveri H, Pitkala KH. Malnutrition and associated factors among aged residents in all nursing homes in Helsinki. Eur J Clin Nutr 2005;59:578-583. doi: 1602111 (pii).

25. Saarela RKT, Muurinen S, Suominen MH, Savikko NN, Soini H, Pitkala KH. Changes in malnutrition and quality of nutritional care among aged residents in all nursing homes and assisted living facilities in Helsinki 2003-2011. Arch Gerontol Geriatr 2017;72:169-173. doi: S0167-4943(17)30241-8 (pii).

26. Suominen MH, Jyvakorpi SK, Pitkala KH, Finne-Soveri H, Hakala P, Mannisto S, Soini H, Sarlio-Lahteenkorva S. Nutritional guidelines for older people in Finland. J Nutr Health Aging 2014;18:861-867. doi: 10.1007/s12603-014-0509-1 (doi).

27. Kvamme JM, Olsen JA, Florholmen J, Jacobsen BK. Risk of malnutrition and healthrelated quality of life in community-living elderly men and women: the Tromso study Qual Life Res 2011;20:575-582. doi: 10.1007/s11136-010-9788-0 (doi).

28. Johansson L, Sidenvall B, Malmberg B, Christensson L. Who will become malnourished? A prospective study of factors associated with malnutrition in older persons living at home. J Nutr Health Aging 2009;13:855-861.

29. Keller HH, Ostbye T, Goy R. Nutritional risk predicts quality of life in elderly community-living Canadians. J Gerontol A Biol Sci Med Sci 2004;59:68-74.

30. Guallar-Castillon P, Sendino AR, Banegas JR, Lopez-Garcia E, Rodriguez-Artalejo F. Differences in quality of life between women and men in the older population of Spain. Soc Sci Med 2005;60:1229-1240. doi: S0277-9536(04)00347-8 (pii).

31. Bell CL, Tamura BK, Masaki KH, Amella EJ. Prevalence and Measures of Nutritional Compromise Among Nursing Home Patients: Weight Loss, Low Body Mass Index, Malnutrition, and Feeding Dependency, A Systematic Review of the Literature. Journal of the American Medical Directors Association 2013;14:94-100. doi: https:// doi-org.libproxy.helsinki.fi/10.1016/j.jamda.2012.10.012

32. Mjorud M, Kirkevold M, Rosvik J, Selbaek G, Engedal K. Variables associated to quality of life among nursing home patients with dementia. Aging Ment Health 2014;18:1013-1021. doi: 10.1080/13607863.2014.903468 (doi).

33. Bruvik FK, Ulstein ID, Ranhoff AH, Engedal K. The quality of life of people with dementia and their family carers. Dement Geriatr Cogn Disord 2012;34:7-14. doi: $10.1159 / 000341584$ (doi)

34. Hoe J, Hancock G, Livingston G, Woods B, Challis D, Orrell M. Changes in the quality of life of people with dementia living in care homes. Alzheimer Dis Assoc Disord 2009;23:285-290. doi: 10.1097/WAD.0b013e318194fc1e (doi).

35. Hughes CP, Berg L, Danziger WL, Coben LA, Martin RL. A new clinical scale for the staging of dementia. Br J Psychiatry 1982;140:566-572. doi: S0007125000112085 (pii). 